Article

\title{
Curine Inhibits Macrophage Activation and Neutrophil Recruitment in a Mouse Model of Lipopolysaccharide-Induced Inflammation
}

\author{
Jaime Ribeiro-Filho ${ }^{1, * \mathbb{D}}$, Fagner Carvalho Leite ${ }^{2}$, Andrea Surrage Calheiros ${ }^{3}$, \\ Alan de Brito Carneiro ${ }^{3}$, Juliana Alves Azeredo ${ }^{3}$, Edson Fernandes de Assis ${ }^{3}$, \\ Celidarque da Silva Dias ${ }^{4}$, Márcia Regina Piuvezam ${ }^{2}$ and Patrícia T. Bozza ${ }^{3}$ \\ 1 Laboratório de Investigação em Genética e Hematologia Translacional, Instituto Gonçalo Moniz, FIOCRUZ, \\ Salvador 40296-710, Brazil \\ 2 Laboratório de Imunofarmacologia, Departamento de Fisiologia e Patologia, UFPB, João Pessoa 58051-900, \\ Brazil; fagnercarvalho.farm@gmail.com (F.C.L.); mrpiuvezam@ltf.ufpb.br (M.R.P.) \\ 3 Laboratório de Imunofarmacologia, Instituto Oswaldo Cruz, FIOCRUZ, Rio de Janeiro 21040-360, Brazil; \\ andrea.surrage@gmail.com (A.S.C.); alan.fiocruz@gmail.com (A.d.B.C.); jazeredo@ioc.fiocruz.br (J.A.A.); \\ edassis@ioc.fiocruz.br (E.F.d.A.); pbozza@gmail.com (P.T.B.) \\ 4 Laboratório de Fitoquímica, Departamento de Ciências Farmacêuticas, UFPB, João Pessoa 58051-900, Brazil; \\ celidarquedias@ltf.ufpb.br \\ * Correspondence: jaime.ribeiro@fiocruz.br; Tel.: +55-71-3176-2226
}

Received: 18 September 2019; Accepted: 22 October 2019; Published: 3 December 2019

\begin{abstract}
Curine is a bisbenzylisoquinoline alkaloid (BBA) with anti-allergic, analgesic, and antiinflammatory properties. Previous studies have demonstrated that this alkaloid is orally active at non-toxic doses. However, the mechanisms underlying its anti-inflammatory effects remain to be elucidated. This work aimed to investigate the effects of curine on macrophage activation and neutrophil recruitment. Using a murine model of lipopolysaccharide (LPS)-induced pleurisy, we demonstrated that curine significantly inhibited the recruitment of neutrophils in association with the inhibition of cytokines tumor necrosis factor (TNF- $\alpha$ ), interleukin (IL)-1 $\beta$, IL-6, monocyte chemotactic protein (CCL2/MCP-1) as well as leukotriene $\mathrm{B}_{4}$ in the pleural lavage of mice. Curine treatment reduced cytokine levels and the expression of iNOS in in vitro cultures of macrophages stimulated with LPS. Treatment with a calcium channel blocker resulted in comparable inhibition of TNF- $\alpha$ and IL-1 $\beta$ production, as well as iNOS expression by macrophages, suggesting that the anti-inflammatory effects of curine may be related to the inhibition of calcium-dependent mechanisms involved in macrophage activation. In conclusion, curine presented anti-inflammatory effects that are associated with inhibition of macrophage activation and neutrophil recruitment by inhibiting the production of inflammatory cytokines, $\mathrm{LTB}_{4}$ and nitric oxide (NO), and possibly by negatively modulating $\mathrm{Ca}^{2+}$ influx.
\end{abstract}

Keywords: Curine; alkaloid; macrophage; neutrophil; lipopolysaccharide

Key Contribution: This study attempts to contribute to the elucidation of mechanisms involved in the anti-inflammatory action of curine, an orally active alkaloid.

\section{Introduction}

Macrophages work as detectors of inflammatory signals, including those produced by the host and the derived from microorganisms, such as lipopolysaccharide (LPS) [1]. LPS signaling through $\mathrm{TLR}_{4}$ induces macrophage activation by regulating intracellular pathways involved in cytokine, 
lipid mediator and oxygen reactive species (ROS) production, in a process regulated by calcium signaling [2,3]. The mediators released by activated macrophages play critical roles in neutrophil recruitment and activation, and therefore, influence the progress of immune responses as well as the development of many inflammatory diseases [4,5].

Curine (Figure 1A) is the principal bisbenzilisoquinoline alkaloid (BBA) obtained from Chondrodendron platyphyllum (Menispermaceae). Earlier studies reported that this alkaloid, as well as the structurally related compounds isocurine and 12-O-metilcurine, have promising pharmacological effects [6] corroborating ethnopharmacological data which points C. phatyphyllum as a plant with medicinal properties [7]. Studies have shown that BBA are bioactive natural compounds presenting anti-inflammatory, anti-allergic, and analgesic activities [8] and there is evidence that their mechanism of action involves a direct inhibition of calcium channels $[6,9,10]$.

Studies carried out by our group have demonstrated the effects of curine treatment in an experimental model of allergic asthma. The oral administration of this compound to allergic mice significantly inhibited eosinophilic inflammation and airway hyper-responsiveness (AHR), which are critical hallmarks of the allergic response in this model. In addition, curine prevented lipid body formation and cytokine production in vivo, suggesting that it has an inhibitory role in eosinophil activation. A similarity between the anti-allergic effects of curine and verapamil (a calcium channel blocker) as well as inhibition of calcium-induced tracheal contraction by curine strongly suggested that its anti-allergic effects are associated with modulation of calcium-dependent responses [11]. These findings were affirmed by another study in which we demonstrated the anti-allergic effects of curine and verapamil in a mice model of mast cell activation. In addition to inhibiting the scratching behavior, the oral treatment with curine prevented the anaphylactic shock reaction in systemically-challenged mice. Additionally, these treatments inhibited the production of lipid mediators and cytokines associated with mast cell activation [12]. Importantly, an analysis of physical, behavioral, histological, hematologic and biochemical parameters revealed that the oral treatment with curine for seven consecutive days did not induce evident toxicity in mice [11]. Additionally, this alkaloid presented analgesic effects that were not associated with an activity in the central nervous system but involve anti-inflammatory mechanisms [13].

Accumulating evidence places curine as a potent anti-inflammatory and anti-allergic compound with low-toxicity. Through both in vivo and in vitro studies, we have described the general pharmacological properties of this alkaloid. However, the mechanisms underlying its anti-inflammatory effects are still poorly understood. Therefore, the objective of this study was to investigate the effects of curine on macrophage activation and neutrophil recruitment in a mouse model of LPS-induced inflammation. Here we analyze the impact of inflammatory mediator production modulation as well as the importance of calcium influx inhibition in the anti-inflammatory mechanisms of curine.

\section{Results}

\subsection{Curine Inhibits Neutrophil Recruitment in LPS-Challenged Mice}

An intrapleural administration of LPS was observed to induce a significant increase in the number of neutrophils in the pleural lavages of $\mathrm{C} 57 \mathrm{Bl} / 6$ mice (Figure 1B). The oral treatment with curine $(2.5 \mathrm{mg} / \mathrm{kg})$ or dexamethasone $(2 \mathrm{mg} / \mathrm{kg}) 1 \mathrm{~h}$ prior to the LPS challenge caused a significant reduction in neutrophil counts (Figure 1B) in comparison with the group of untreated and challenged mice, thus demonstrating the inhibitory role played by curine with regard to neutrophil recruitment during the pleural inflammation. 
A

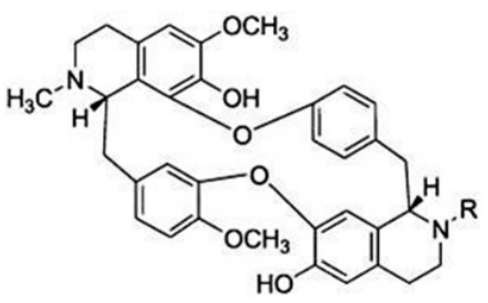

B

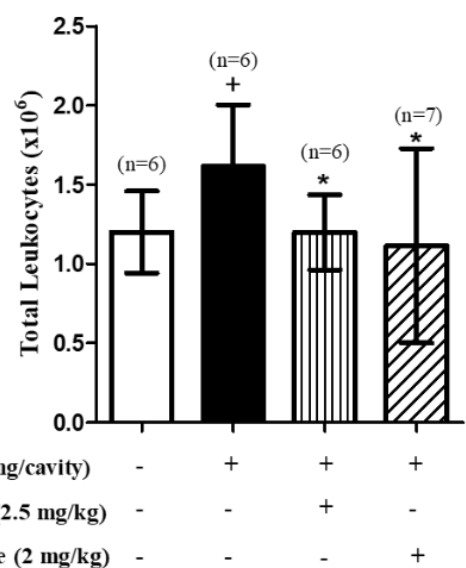

C

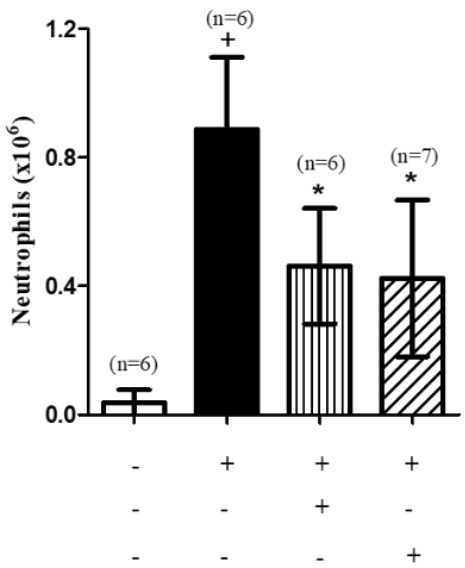

Figure 1. Effect of curine on neutrophil recruitment in lipopolysaccharide (LPS)-induced pleurisy. (A) The chemical structure of curine. Total leukocytes (B) and neutrophils (C) per pleural lavage of C57Bl/6 mice orally pre-treated with curine $(2.5 \mathrm{mg} / \mathrm{kg})$ or dexamethasone $(2 \mathrm{mg} / \mathrm{kg})$, counted under light microscopy $4 \mathrm{~h}$ after LPS-challenge. Results are expressed as means \pm SD from at least six animals. + significant difference $(p<0.05)$ from the unchallenged group; ${ }^{*}$ significant difference $(p<0.05)$ from the untreated LPS-challenged group. Statistical significance was determined with one-way ANOVA and post hoc Tukey test.

\subsection{Curine Inhibits Inflammatory Mediator Production in Vivo}

Based on our finding of increased neutrophil recruitment in response to the LPS challenge, we analyzed the effect of curine treatment on the production of mediators involved in neutrophil recruitment and inflammation. Supernatants obtained from the pleural lavages of LPS-challenged mice presented increased levels of inflammatory mediators (Figure 2A-F), in comparison to unstimulated animals. Curine treatment was observed to significantly inhibit the production of interleukin (IL)-6, tumor necrosis factor (TNF)- $\alpha$, monocyte chemotactic protein (MCP)-1/CCL2, keratinocyte-derived chemokine (KC/CXCL1) and leukotriene $\mathrm{B}_{4}\left(\mathrm{LTB}_{4}\right)$, thereby providing evidence of a link between the inhibitory effect of curine on neutrophil recruitment and associated inflammatory mediator production.

\subsection{Curine Inhibits Macrophage Activation in Vitro}

As activated macrophages are crucially involved in the production of mediators in early inflammatory events, we analyzed the direct effects of curine on macrophage activation by investigating its interference on cytokine production in vitro. Figure 3 shows that stimulation of peritoneal macrophage cultures with LPS increased the levels of IL-1 $\beta$, IL- 6 and TNF- $\alpha$ in comparison with control cells. Pre-treatment with curine at 1 or $10 \mu \mathrm{M}$ significantly reduced the levels of these cytokines in the supernatants indicating that this BBA inhibits TLR-4 mediated macrophage activation in vitro (Figure 3). 

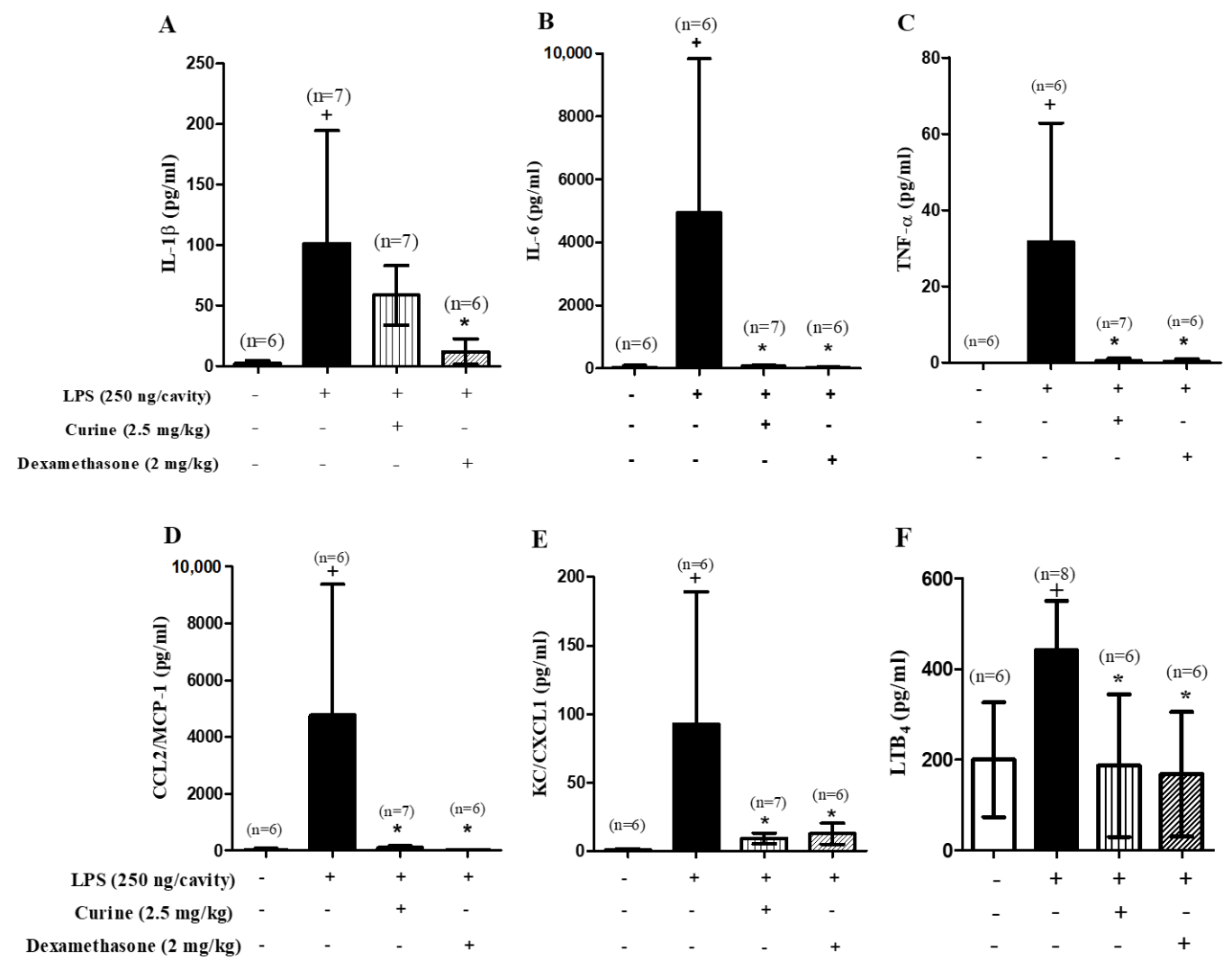

Figure 2. Effects of curine pre-treatment on in vivo cytokine production $4 \mathrm{~h}$ after LPS challenge. Concentrations of interleukin (IL)-1 $\beta$ (A), IL-6 (B), tumor necrosis factor (TNF)- $\alpha$ (C), CCL2/monocyte chemotactic protein (MCP)-1 (D), keratinocyte-derived chemokine (KC/CXCL-1) (E) and leukotriene $\mathrm{B}_{4}$ $\left(\mathrm{LTB}_{4}\right)(\mathrm{F})$ in the pleural lavages of $\mathrm{C} 57 \mathrm{Bl} / 6$ mice orally pre-treated with curine $(2.5 \mathrm{mg} / \mathrm{kg})$ or dexamethasone $(2 \mathrm{mg} / \mathrm{kg})$. These results are expressed as the mean \pm SD of at least 6 animals. + significant difference $(p<0.05)$ from the unchallenged group; * significant difference $(p<0.05)$ from the untreated LPS-challenged group. Statistical significance was determined with one-way ANOVA and post hoc Tukey test. Assay range of IL-1 $\beta$ : 10.36-60,631 pg/mL; IL-6: 0.74-12,053 pg/mL; TNF- $\alpha$ : 5.86-59,626 pg/mL; CCL2/MCP-1: 22.4-41,873 pg/mL; KC/CXCL1: 3.2-182 pg/mL and $\mathrm{LTB}_{4}: 3.9-500 \mathrm{pg} / \mathrm{mL}$.
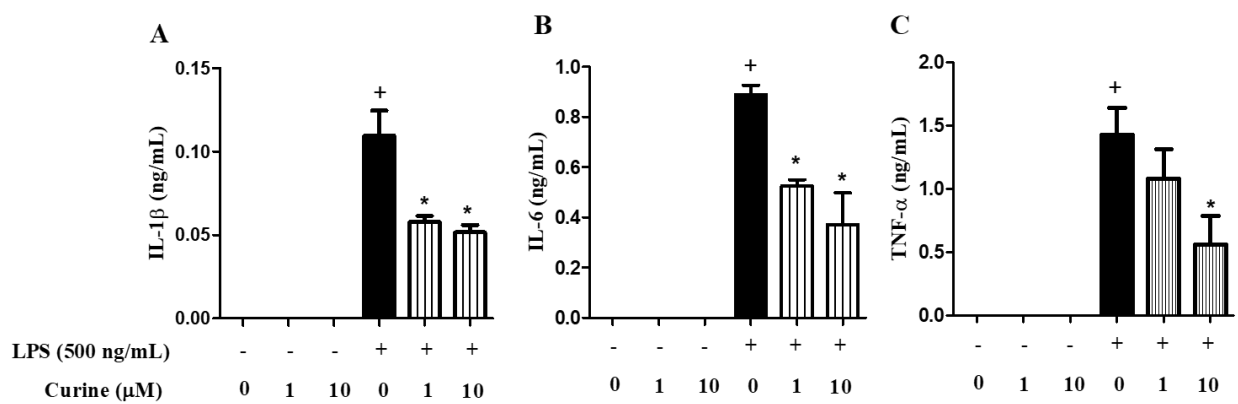

Figure 3. Effects of curine treatment on macrophage activation $4 \mathrm{~h}$ after LPS challenge. Concentrations of IL-1 $\beta$ (A), IL-6 (B) and TNF- $\alpha$ (C) in the supernatants of peritoneal macrophage cultures treated with curine $(1$ or $10 \mu \mathrm{M}) 4 \mathrm{~h}$ after the stimulus with LPS $(500 \mathrm{ng} / \mathrm{mL})$. Results are expressed as means \pm Standard Error of Mean (SEM) of two experiments performed in triplicate. + significant difference $(p<0.05)$ from the unchallenged cells; * significant difference $(p<0.05)$ from the untreated LPS-challenged cells. Statistical significance was determined with one-way ANOVA and post hoc Tukey test. Assay range of IL-1 $\beta$ and IL-6: $15.6-1000$ pg/mL and TNF- $\alpha$ : $31.3-2000$ pg/mL. 


\subsection{Effects of Calcium Influx Inhibition on Macrophage Activation}

Our group recently demonstrated that curine and verapamil presented anti-allergic effects that might be associated with calcium signaling modulation [11,12]. To evaluate the importance of calcium influx inhibition on macrophage activation, as well as its potential participation in curine anti-inflammatory mechanisms, we made a comparison between the effects of curine and verapamil on macrophage activation. As shown in Figure 4, treatment with curine or verapamil at the same concentration induced a similar inhibition in IL-1 $\beta$ (A) and TNF- $\alpha$ (B) production, which suggests that the effects of curine on macrophage activation might be dependent on calcium influx inhibition.

A

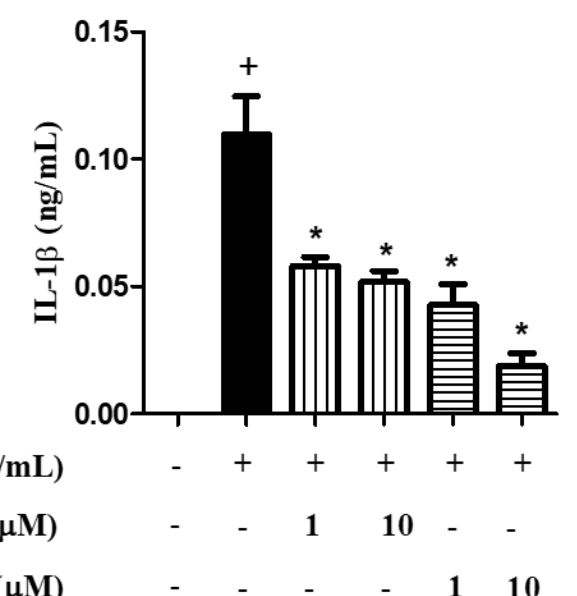

B

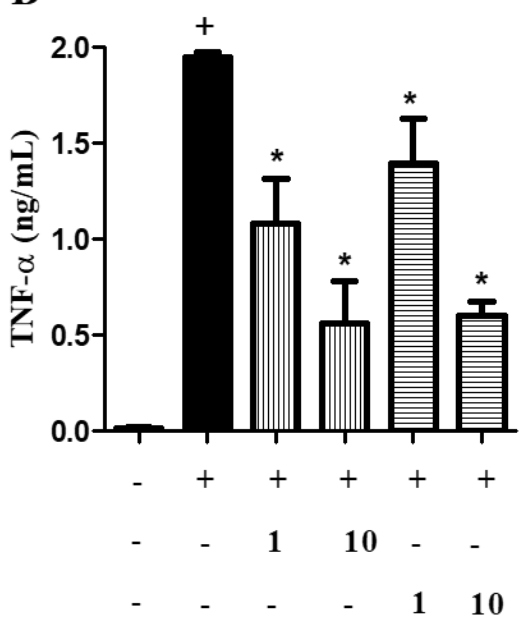

Figure 4. Effects of calcium influx inhibition on macrophage activation. Concentrations of IL-1 $\beta$ (A), TNF- $\alpha(B)$ in the supernatants of peritoneal macrophage cultures treated with curine or verapamil ( 1 or $10 \mu \mathrm{M}$ ) were evaluated $4 \mathrm{~h}$ after LPS challenge. Results are expressed as means \pm SEM from two experiments performed in triplicate. + significant difference $(p<0.05)$ from the unchallenged cells; * significant difference $(p<0.05)$ from the untreated LPS-challenged cells. Statistical significance was determined with one-way ANOVA and post hoc Tukey test. Assay range of IL-1ß: 15.6-1000 pg/mL and TNF- $\alpha$ : 31.3-2000 pg/mL.

\subsection{Curine Inhibits Nitric Oxide (NO) Production by Regulating iNOS Expression in Macrophages}

It has been demonstrated that LPS stimulates the synthesis of NO via IL- $1 \beta$, TNF- $\alpha$, and IFN- $\gamma$ [14]. Figure 5A illustrates the effects of curine on NO production. The supernatants of LPS-stimulated peritoneal macrophages presented significantly increased concentrations of nitrite, which was significantly decreased by curine treatment. Moreover, while LPS stimulation was found to induce increased expression of iNOS by macrophages, treatment with curine or verapamil reduced the expression of this enzyme (Figure 5B). These findings suggest that the inhibition of NO production through the curine-mediated regulation of iNOS expression could be associated with calcium influx inhibition. 
A

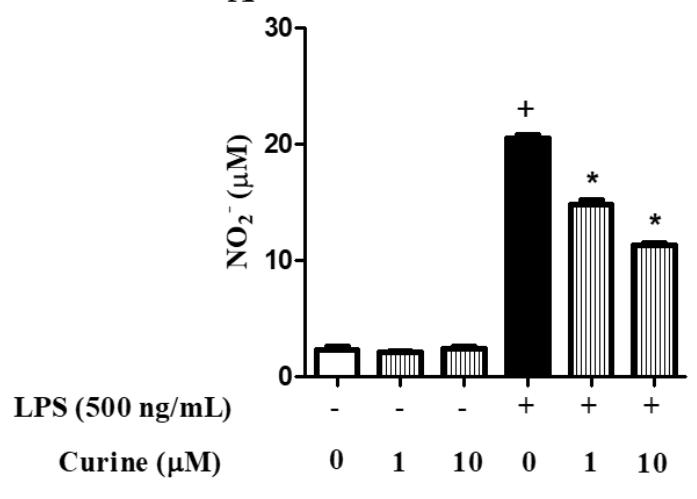

B

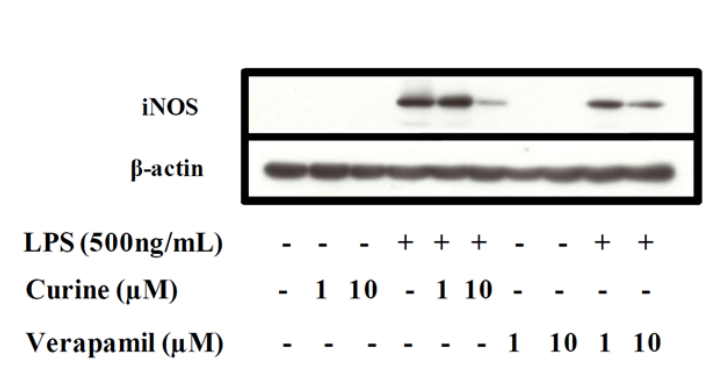

Figure 5. Effects of curine on nitric oxide $(\mathrm{NO})$ production and iNOS expression. Concentrations of nitrite (A) in the supernatants of peritoneal macrophages treated with curine or verapamil (1 or 10 $\mu \mathrm{M}) 24 \mathrm{~h}$ after LPS challenge. iNOS expression (B) was analyzed by Western blotting $18 \mathrm{~h}$ after LPS stimulus. Results are expressed as means \pm SEM from two experiments performed in triplicate. + significant difference $(p<0.05)$ from the unchallenged cells; ${ }^{*}$ significant difference $(p<0.05)$ from the untreated LPS-challenged cells. Statistical significance was determined with one-way ANOVA and post hoc Tukey test.

\section{Discussion}

The bisbenzylisoquinoline alkaloids (BBA) constitute a group of secondary metabolites that exert numerous biological effects. The medicinal properties of BBA-rich plants and isolated compounds have been demonstrated in different experimental models, indicating that this class of substances presents promising anti-allergic and anti-inflammatory activities $[15,16]$. Our group found that curine, a BBA identified as the main constituent of Chondrodendron platyphyllum (Menispermaceae), is an orally active alkaloid with potent immunomodulatory effects and low toxicity, which therefore makes it a promising candidate in the development of new anti-inflammatory drugs [16].

In a worldwide context, questions have been raised concerning the efficacy and safety of currently available medications [17]. Although corticosteroids, non-steroidal anti-inflammatory drugs (NSAIDs) and other conventional drugs effectively relieve most inflammatory symptoms, in specific conditions these are not effective, or can cause significant side effects [18]. Accordingly, the development of novel, safe and effective drugs is imperative to improving anti-inflammatory therapy.

Although inflammatory diseases differ in various aspects, some evidence has consistently shown that macrophages and neutrophils perform essential functions in the initiation and development of many inflammatory conditions [19]. The present mouse model of LPS-induced inflammation, used to characterize the effects of curine on macrophage activation and neutrophil recruitment, demonstrated new anti-inflammatory properties of this alkaloid compound. Our findings indicate that orally administered curine inhibited the recruitment of neutrophils to the pleural cavity of LPS-challenged mice. Accordingly, curine treatment reduced levels of IL-6, TNF- $\alpha$, CCL2/MCP- 1 , and $\mathrm{LTB}_{4}$ in the pleural lavages of these animals, providing evidence of a link between the inhibitory effect of this alkaloid on neutrophil in association with the production of inflammatory mediators.

Neutrophils can rapidly migrate to sites of inflammation [20] in response to inflammatory signals such as chemokines and cytokines produced by resident cells [1]. The chemokine CXCL1 (also known as $\mathrm{KC}$ in mice) plays a critical role in neutrophil recruitment and activation by signaling via CXCR2 on these cells [21]. Previous studies have also demonstrated that $\mathrm{LTB}_{4}$ acts as an essential chemotactic agent $[22,23]$ by stimulating the recruitment of neutrophils via $\mathrm{BLT}_{1}$ receptor activation [24]. It follows that the inhibitory effect of curine on KC/CCL1 and $\mathrm{LTB}_{4}$ production might therefore directly impact neutrophil recruitment. Additionally, LPS-induced cytokines, including TNF- $\alpha$ and IL- $\beta$, can directly 
affect neutrophil recruitment by stimulating the expression of adhesion molecules, including selectins and integrins [25-27].

As activated macrophages are one of the most critical sources of mediator production in the early phase of inflammation [28], we hypothesized that the inhibition of neutrophil recruitment and cytokine production in the pleural lavage induced by curine might be associated with decreased macrophage activation. Our data show that the production of IL-6, IL- $\beta$, and TNF- $\alpha$ was inhibited in murine macrophages stimulated with curine in vitro, which indicates that this compound may regulate neutrophil recruitment by inhibiting the production of key inflammatory mediators in macrophages. On the other hand, the release of products involved in monocyte/macrophage influx and activation, such as MCP-1, by neutrophils can also affect macrophage function [29]. Here, MCP-1 production was found to be significantly inhibited by curine, which suggests that cross-talk between neutrophils and macrophages could be impaired by curine treatment.

Our previous work has demonstrated that curine can exert anti-allergic effects associated with the inhibition of calcium influx $[11,12,16]$. Using tracheal rings preparations kept in $\mathrm{Ca}^{2+}$-free medium, depolarized with $\mathrm{KCl}$ and stimulated with cumulative addition of $\mathrm{Ca}^{2+}$, Ribeiro-Filho and colleagues [11] demonstrated ex-vivo that curine pre-treatment significantly inhibited calcium-induced trachea contractile response, suggesting that curine inhibits the influx of calcium via blockade of voltage-dependent $\mathrm{Ca}^{2+}$ channels in the rat tracheal smooth muscle. In addition, Medeiros and collaborators [10] demonstrated that curine decreased intracellular $\mathrm{Ca}^{2+}$ transients in $\mathrm{A} 7 \mathrm{r} 5$ cells, which indicated that this alkaloid can have a direct inhibitory effect on L-type $\mathrm{Ca}^{2+}$ channels in vascular smooth muscle cells. Here we hypothesized that calcium influx inhibition would impair macrophage activation, which could be partially responsible for the anti-inflammatory effects associated with curine treatment. To confirm this, we compared the impact of verapamil and curine on cytokine production by LPS-stimulated macrophages, as a parameter to evaluate macrophage activation. When administered under identical conditions (concentrations and time of pre-treatment), verapamil and curine demonstrated similar inhibitory effects, suggesting that the modulation of calcium influx is indeed a potential mechanism by which curine inhibits the inflammatory response.

Curine was also found to significantly decrease nitrite concentrations in the supernatants of macrophages stimulated with LPS, indicating that nitric oxide (NO) production was inhibited in vitro. This finding adds to the role played by curine in macrophage activation, since NO production is a hallmark of activated macrophages [14]. Importantly, recent reports have demonstrated that $\mathrm{NO}$, in association with other ROS, is critically involved in neutrophil extracellular trap (NET) formation [30]. Curiously, it was also recently reported that neutrophils might participate in the resolution of inflammation mediated by reparative macrophages [5]. It has been well established that LPS and inflammatory cytokines stimulate NO production by inducing iNOS expression [31]. Here, we demonstrated that curine and verapamil inhibited the expression of iNOS in LPS-stimulated murine macrophages, which thereby provides evidence of the inhibitory effect of these drugs on NO production. This finding further corroborates the impact of curine on TNF- $\alpha$ and IL-1 $\beta$ production and lends support to the notion that curine negatively modulates macrophage activation through the inhibition of a calcium-dependent response. In fact, studies have shown that calcium-dependent signaling potentiates macrophage activation [32] and stimulates proinflammatory cytokine production [33] in these cells. Therefore, further studies addressing the role of curine in modulating calcium influx and associated signaling pathways in immune cells, including macrophages, will contribute to characterize the molecular mechanism of action of curine as an anti-inflammatory compound.

We previously reported that a single dose of curine administered orally as pre-treatment exhibited anti-inflammatory and analgesic effects in mice [13]. Our investigation of the analgesic effects of curine revealed that instead of acting by way of neurogenic mechanisms, curine acts through anti-inflammatory mechanisms associated with the inhibition of $\mathrm{PGE}_{2}$ production. These findings are in line with our previous work which demonstrated that curine inhibited the synthesis of cysteinyl leukotrienes and $\mathrm{PGD}_{2}$ by mast cells [12]. Taken together, these findings indicate that curine affects signaling pathways 
involved in lipid mediator synthesis, possibly due to interference in leukocyte activation. Finally, the present findings suggest that the anti-inflammatory and analgesic effects of curine are also related to the inhibition of critical mediators of inflammatory pain, including IL-1 $\beta$, TNF- $\alpha$, and NO [34-36].

In conclusion, curine was shown to exert anti-inflammatory effects associated with the inhibition of macrophage activation and neutrophil recruitment, as well as reduced production of inflammatory cytokines, LTB4, NO and the modulation of $\mathrm{Ca}^{2+}$ influx (Figure 6).

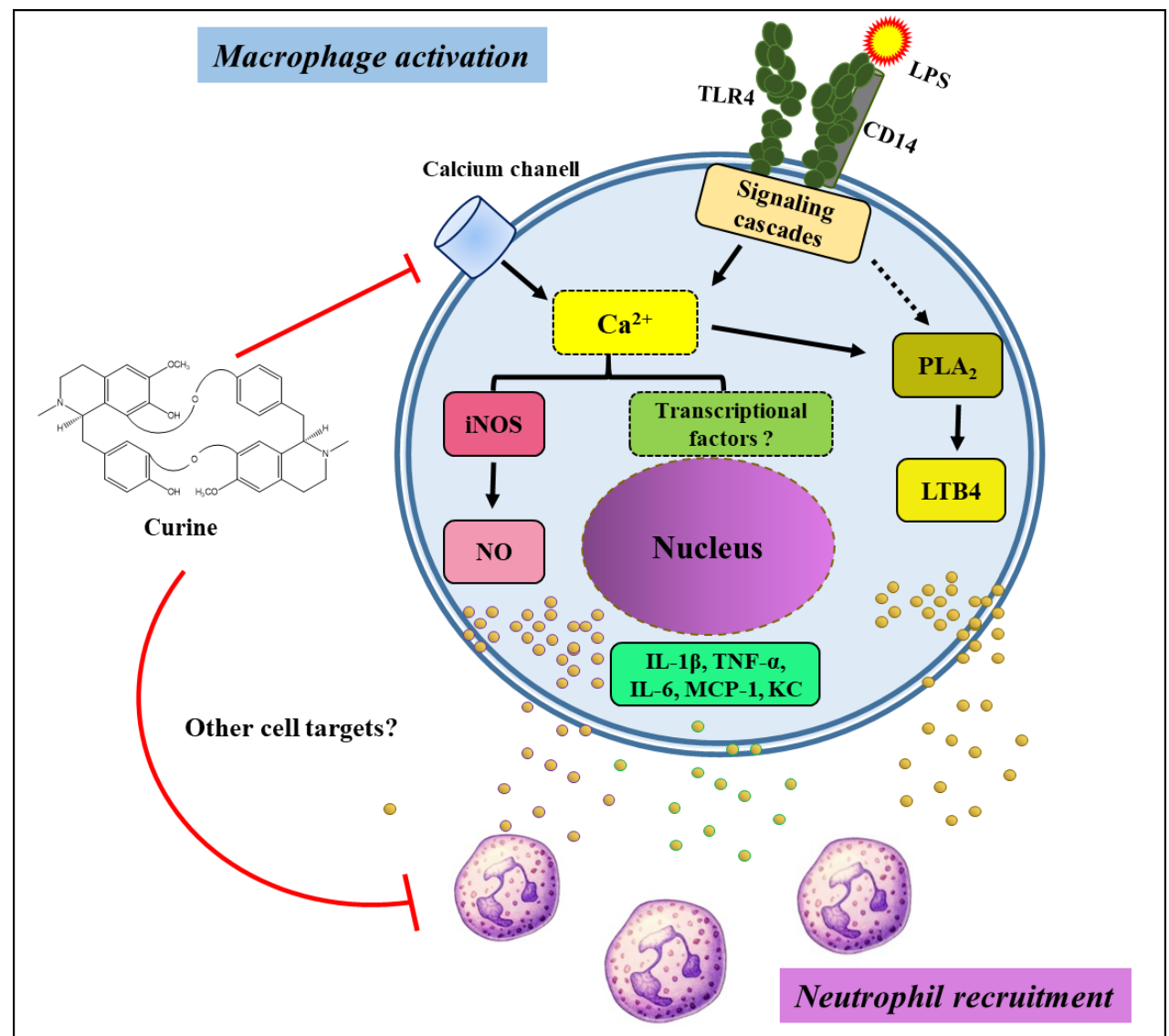

Figure 6. Schematic diagram illustrating a potential mechanism of action by curine on macrophage activation and neutrophil recruitment. The inhibition of calcium influx could be affecting signaling pathways associated with the synthesis of $\mathrm{NO}, \mathrm{LTB}_{4}$ and cytokines, which could impair neutrophil recruitment. Importantly, the possibility that curine may interfere with other cell targets cannot be ruled out.

\section{Materials and Methods}

\subsection{Preparation of Curine Solution}

Curine was purified from the total tertiary alkaloid fraction (TTA) obtained from the root bark of Chondrodendron platyphyllum Hil St. (Miers) as previously described [13]. The TTA was submitted to column chromatography followed by thin-layer chromatography (TLC) purification, from which curine was obtained in the form of a crystal. The chemical structure was analyzed by spectroscopy and comparison with the literature data [37]. The purity of curine was analyzed by NMR ${ }^{13} \mathrm{C}$ and $\mathrm{NMR}{ }^{1} \mathrm{H}$ $\left(\mathrm{CDCl}_{3}, 400 \mathrm{MHz}\right)$ data from the crystals when compared to the literature data [13] and the substance was considered spectroscopically pure. After purification, $1 \mathrm{mg}$ of the crystal was dissolved in $50 \mu \mathrm{L}$ of $1 \mathrm{~N} \mathrm{HCl}$ and $500 \mu \mathrm{L}$ of distilled water. The $\mathrm{pH}$ was adjusted (between 7-8) with $1 \mathrm{~N} \mathrm{NaOH}$ and volume was adjusted to $1000 \mu \mathrm{L}$, with dilutions performed in phosphate-buffered saline (PBS). The use of C. platyphyllum in the present study was registered in the National System of Genetic Heritage Management and Associated Traditional Knowledge (SisGen, protocol A84A87E). 


\subsection{Animals}

Male C57Bl/6 mice (age 6-8 weeks) weighing 20-30 g obtained from the Oswaldo Cruz (Fiocruz, Rio de Janeiro, Brazil) were maintained with food and water ad libitum in cages at room temperature ranging from 22 to $24{ }^{\circ} \mathrm{C}$ under a $12 \mathrm{~h}$ light/dark cycle. This study was carried out in accordance with the recommendations established by the Brazilian National Council for the Control of Animal Experimentation (CONCEA). All experimental protocols were approved by the Animal Welfare Committee of the Oswaldo Cruz Foundation (CEUA/FIOCRUZ-RJ, protocol \#L-002/08).

\subsection{Treatments}

For in vivo experimentation, animals (6-8 per group) were randomly assigned by body weight for single oral pre-treatment with curine $(2.5 \mathrm{mg} / \mathrm{kg})$, dexamethasone $(2 \mathrm{mg} / \mathrm{kg})$ or PBS (negative control). All treatments were performed by simple awake gavage $[38,39] 1 \mathrm{~h}$ prior to LPS challenge. Briefly, treatments $(0.1 \mathrm{~mL} / 10 \mathrm{~g}$ body weight $)$ were administered using a $31 \mathrm{~mm}$ long, $1 \mathrm{~mm}$ diameter reusable curved stainless-steel feed needle containing a $1.7 \mathrm{~mm}$ ball at the tip (Bronther, Ribeirão Preto, $\mathrm{SP}, \mathrm{Brazil})$. The gavage needle was gently inserted into the oral cavity, ensuring the correct passage through the esophagus. For in vitro experiments, cells were treated with curine or verapamil 1 or $10 \mu \mathrm{M})$ or PBS $1 \mathrm{~h}$ before stimulation. Curine dosage $(2.5 \mathrm{mg} / \mathrm{kg})$ was based on results obtained by Ribeiro-Filho and colleagues [11].

\subsection{LPS-Induced Pleurisy}

Male C57Bl/6 mice ( $n=6-8)$ were orally pre-treated with curine $(2.5 \mathrm{mg} / \mathrm{kg})$ or dexamethasone $(2 \mathrm{mg} / \mathrm{Kg}) 1 \mathrm{~h}$ prior to the pleurisy protocol [40]. Animals were anesthetized with isoflurane (Forane ${ }^{\mathrm{TM}}$, Abbott, São Paulo, SP, Brazil) and challenged through an intrathoracic (i.t) injection of LPS ( $250 \mathrm{ng} /$ cavity) dissolved in $100 \mu \mathrm{L}$ of PBS. A group of mice receiving the same volume of PBS was used as the control. Four hours following the LPS injection, the animals were euthanized by $\mathrm{CO}_{2}$ and the pleura was surgically exposed. Pleural lavage was collected by washing the pleural cavity with $1 \mathrm{~mL}$ of heparinized PBS (20 U/mL).

\subsection{Leukocyte Counting}

Leukocytes were counted under light microscopy after diluting the pleural lavage samples in Turk fluid ( $2 \%$ acetic acid). Differential counts were performed under an objective lens at $100 \times$ magnification after staining by the May-Grunwald-Giemsa method.

\subsection{Peritoneal Macrophage Cultures}

Peritoneal macrophages from C57B1/6 mice were obtained four days after the injection of $4 \%$ thioglycollate. The peritoneal cavity was washed with RPMI 1640 medium supplemented with $100 \mathrm{U} / \mathrm{mL}$ penicillin and $100 \mu \mathrm{g} / \mathrm{mL}$ streptomycin (Thermo Fisher Scientific, Waltham, MA, USA). Cells were adjusted to $2 \times 10^{6} / \mathrm{mL}$ and plated on 24 -well culture plates $(500 \mu \mathrm{L})$ at $37^{\circ} \mathrm{C}$ under $4 \% \mathrm{CO}_{2}$ overnight. Following incubation, cells were pre-treated with curine, or alternatively with verapamil, (both at 1 or $10 \mu \mathrm{M})$ and stimulated with LPS (500 ng/mL) $1 \mathrm{~h}$ later. Of note, curine pre-treatment (at either 1 or $10 \mu \mathrm{M}$ ) did not affect cell viability, which was higher than $90 \%$ in all experiments.

\subsection{Cytokine and $\mathrm{LTB}_{4}$ Analysis}

Samples of the pleural lavage were centrifuged at $500 \mathrm{~g}$ for $8 \mathrm{~min}$ at $4{ }^{\circ} \mathrm{C}$ to obtain the supernatants. The concentrations of IL-1 $\beta$, IL-6, TNF- $\alpha$, CCL2/MCP- 1 and KC/CXCL-1 in these supernatants were determined using a multiplex fluorescent microbead immunoassay (Bio-Rad Laboratories, Hercules, CA, USA). Cytokine levels were quantified using a Luminex technology (Bio-Plex Workstation; Bio-Rad Laboratories, Hercules, CA, USA). Data analysis was performed using Bio-Plex software (Bio-Rad Laboratories, Hercules, CA, USA). The concentrations of $\mathrm{LTB}_{4}$ in the pleural lavages, as well as 
cytokines in the supernatants of macrophage cultures, were analyzed using ELISA kits in accordance with the manufacturer's instructions (Cayman Chemical, Ann Arbor, MI, USA: LTB 4 and R\&D Systems, Minneapolis, MN, USA: Cytokines). All analyses were performed $4 \mathrm{~h}$ after stimulation with LPS.

\subsection{Nitrite Quantification}

For $\mathrm{NO}_{2}{ }^{-}$determination, $100 \mu \mathrm{L}$ of macrophage culture supernatant was removed $24 \mathrm{~h}$ after LPS stimulus and incubated with Griess reagent (1\% sulfanilamide and $0.1 \%$ naphthylenediamine hydrochloride in $2.5 \% \mathrm{H}_{3} \mathrm{PO}_{4}$ ) for $10 \mathrm{~min}$ at room temperature. The readings were performed at $540 \mathrm{~nm}$ using a spectrophotometer (Titertek Multiscan, Flow Laboratories, Eflab Oy, Helsinki, Finland). Nitrite concentrations were calculated using a standard reference curve obtained from $\mathrm{NaNO}_{2}(1-200 \mu \mathrm{M}$ in culture medium).

\subsection{SDS-PAGE and Western Blotting}

Eighteen hours after LPS stimulus, Western blot was used to analyze iNOS expression. Briefly, cells were washed in PBS buffer and homogenized with $10 \mathrm{mM}$ Tris-HCl buffer (pH 7.4), $150 \mathrm{mM} \mathrm{NaCl}, 0.5 \%$ triton X-100, 10\% glycerol (v/v), $0.1 \mathrm{mM}$ EDTA, $1 \mathrm{mM}$ Dithiothreitol (DTT) and a cocktail of protease inhibitors (Roche Diagnostics $\mathrm{GmbH}$, Mannheim, Germany). Proteins from the cell homogenate were separated by polyacrylamide gels in the presence of $10 \%$ SDS at a constant current of $16 \mathrm{~mA}$. Full-range rainbow molecular weight markers (RPN800E, GE Healthcare Life Sciences, Piscataway, NJ, USA) were used as a relative molecular mass standard. After running the gels, samples were transferred at $200 \mathrm{~mA}\left(2.7 \mathrm{~mA} / \mathrm{cm}^{2}\right)$ to a nitrocellulose membrane using $25 \mathrm{mM}$ Tris- $\mathrm{HCl}$ and $192 \mathrm{mM}$ glycine, $\mathrm{pH} \mathrm{8.3,}$ at $4{ }^{\circ} \mathrm{C}$ for $120 \mathrm{~min}$. The membranes were then blocked with Tris-buffered saline (TBS)-0.5 tween 20 and $5 \%$ milk for $1 \mathrm{~h}$ at room temperature, incubated with a polyclonal antibody (1:1000) against iNOS (BD-610333) for $18 \mathrm{~h}$ at $4{ }^{\circ} \mathrm{C}$, followed by incubation with a secondary antibody (anti-rabbit IgG-HRP, PI.1000, Vector Laboratories) for $1 \mathrm{~h}$ at room temperature. Reactions were developed using a Super Signal West Pico Chemiluminescent Substrate (Thermo Fisher Scientific, Rockford, IL, USA).

\subsection{Statistical Analyses}

Data were analyzed by one-way ANOVA followed by Tukey's post-test using GraphPad Prism software version 5.02 (GraphPad, San Diego, CA, USA, 2016). Values of in vivo experiments are expressed as means \pm SD and values of in vitro assays as means \pm Standard Error of Mean (SEM). Statistical significance was considered when $p<0.05$.

Author Contributions: Conceptualization: J.R.-F., P.T.B.; experiments were conducted by: J.R.-F., F.C.L., A.S.C., A.d.B.C., J.A.A. and E.F.d.A.; data analysis: J.R.-F., P.T.B. and M.R.P.; contribution with reagents/materials/analytical tools: C.d.S.D.; writing of manuscript: J.R.-F.; critical review: P.T.B. and M.R.P.

Funding: This work was supported by PRONEX/MCT, CNPq, FAPERJ and INCT-Cancer.

Acknowledgments: The authors would like to thank Cristiane Zanon de Sousa for technical assistance and are grateful to Andris K. Walter for English language revision and copyediting assistance.

Conflicts of Interest: The authors declare no conflicts of interest.

\section{References}

1. Borregaard, N. Neutrophils, from marrow to microbes. Immunity 2010, 33, 657-670. [CrossRef] [PubMed]

2. Dean, J.L.E.; Brook, M.; Clark, A.R.; Saklatvala, J. p38 Mitogen-activated Protein Kinase Regulates Cyclooxygenase-2 mRNA Stability and Transcription in Lipopolysaccharide-treated Human Monocytes. J. Biol. Chem. 1999, 274, 264-269. [CrossRef] [PubMed]

3. Kim, E.; Ha, I.; Kim, K.; Park, D.; Lee, M.Y. Production of TLRs triggered pro-inflammatory cytokines through calcium dependent and independent pathways in HaCaT cells. FASEB J. 2017, 31, 184.6.

4. Kumar, K.P.; Nicholls, A.J.; Wong, C.H.Y. Partners in crime: neutrophils and monocytes/macrophages in inflammation and disease. Cell Tissue Res. 2018, 371, 551-565. [CrossRef] [PubMed] 
5. Yang, W.; Tao, Y.; Wu, Y.; Zhao, X.; Ye, W.; Zhao, D.; Fu, L.; Tian, C.; Yang, J.; He, F.; et al. Neutrophils promote the development of reparative macrophages mediated by ROS to orchestrate liver repair. Nat. Commun. 2019, 10, 1076. [CrossRef] [PubMed]

6. Dias, C.S.; Barbosa-Filho, J.M.; Lemos, V.S.; Cortes, S.F. Mechanisms involved in the vasodilator effect of curine in rat resistance arteries. Planta Med. 2002, 68, 1049-1051. [CrossRef]

7. Correa, P.M. Dicionário Das Plantas Úteis do Brasil e das Exóticas Cultivadas; Instituto Brasileiro de Desenvolvimento Florestal, Ministério da Agricultura: Brasília, Brasil, 1984.

8. Souto, A.L.; Tavares, J.F.; Silva, M.S.; Diniz, M.F.; Athayde-Filho, P.F.; Barbosa-Filho, J.M. Anti-inflammatory activity of alkaloids: An update from 2000 to 2010. Molecules 2011, 16, 8515-8534. [CrossRef]

9. Guedes, D.N.; Barbosa-Filho, J.M.; Lemos, V.S.; Côrtes, S.F. Mechanism of the vasodilator effect of 12-O-methylcurine in rat aortic rings. J. Pharm. Pharmacol. 2002, 54, 853-858. [CrossRef]

10. Medeiros, M.A.; Pinho, J.F.; de-Lira, D.P.; Barbosa-Filho, J.M.; Araújo, D.A.; Cortes, S.F.; Lemos, V.S.; Cruz, J.S. Curine, abisbenzylisoquinoline alkaloid, blocks L-type $\mathrm{Ca}^{2+}$ channels and decreases intracellular $\mathrm{Ca}^{2+}$ transients in A7r5 cells. Eur. J. Pharmacol. 2011, 669, 100-107. [CrossRef]

11. Ribeiro-Filho, J.; Calheiros, A.S.; Vieira-de-Abreu, A.; Carvalho, K.I.M.; Mendes, D.S.; Bandeira-Melo, C.; Martins, M.A.; Dias, C.S.; Piuvezam, M.R.; Bozza, P.T. Curine inibits eosinophil activation and airway hyper-responsiveness in a mouse model of allergic asthma. Toxicol. Appl. Pharmacol. 2013, 273, 19-26. [CrossRef]

12. Ribeiro-Filho, J.; Leite, F.C.; Costa, H.F.; Calheiros, A.S.; Torres, R.C.; de Azevedo, C.T.; Martins, M.A.; Dias, C.S.; Bozza, P.T.; Piuvezam, M.R. Curine inhibits mast cell-dependent responses in mice. J. Ethnopharmacol. 2014, 155, 1118-1124. [CrossRef] [PubMed]

13. Leite, F.C.; Ribeiro-Filho, J.; Costa, H.F.; Salgado, P.R.; Calheiros, A.S.; Carneiro, A.B.; de Almeida, R.N.; Dias Cda, S.; Bozza, P.T.; Piuvezam, M.R. Curine, an Alkaloid Isolated from Chondrodendron platyphyllum Inhibits Prostaglandin $\mathrm{E}_{2}$ in Experimental Models of Inflammation and Pain. Planta Med. 2014, 80, 1072-1078. [CrossRef]

14. Chang, C.I.; Liao, J.C.; Kuo, L. Arginase modulates nitric oxide production in activated macrophages. Am. J. Physiol. 1998, 274, 342-348. [CrossRef]

15. Barbosa-Filho, J.M.; Piuvezam, M.R.; Moura, M.D.; Silva, M.S.; Batista-Lima, K.V.; Leitão-da-Cunha, E.V.; Fechine, I.M.; Takemura, O.S. Anti-inflammatory activity of alkaloids: A twenty-century review. Braz. J. Pharmacogn. 2006, 16, 109-139. [CrossRef]

16. Ribeiro-Filho, J.; Piuvezam, M.R.; Bozza, P.T. Anti-allergic properties of curine, a bisbenzylisoquinoline alkaloid. Molecules 2015, 20, 4695-4707. [CrossRef]

17. Cosendey, M.A.E.; Bermudez, J.A.Z.; Reis, A.L.A.; Silva, H.F.; Oliveira, M.A.; Luiza, V.L. Assistência farmacêutica na atenção básica de saúde: A experiência de três estados brasileiros. Cad. Saúde Pública 2000, 16, 171-182. [CrossRef]

18. Rainsford, K.D. Anti-inflammatory drugs in the 21st century. Sub-Cel. Biochem. 2007, 42, 3-27.

19. Takeda, K.; Akira, S. Toll-like receptors in innate immunity. Int. Immunol. 2005, 17, 1-14. [CrossRef]

20. Amulic, B.; Cazalet, C.; Hayes, G.L.; Metzler, K.D.; Zychlinsky, A. Neutrophil Function: From Mechanisms to Disease. Ann. Rev. Immunol. 2012, 30, 459-489. [CrossRef]

21. Sawant, K.V.; Poluri, K.M.; Dutta, A.K.; Sepuru, K.M.; Troshkina, A.; Garofalo, R.P.; Rajarathnam, K. Chemokine CXCL1 mediated neutrophil recruitment: Role of glycosaminoglycan interactions. Sci. Rep. 2010, 6, 33123. [CrossRef]

22. Palmblad, J.; Malmsten, C.L.; Udén, A.M.; Rådmark, O.; Engstedt, L.; Samuelsson, B. Leukotriene $B_{4}$ is a potent and stereospecific stimulator of neutrophil chemotaxis and adherence. Blood 1981, 58, 658-661. [CrossRef] [PubMed]

23. Afonso, P.V.; Janka-Junttila, M.; Lee, Y.J.; McCann, C.P.; Oliver, C.M.; Aamer, K.A.; Losert, W.; Cicerone, M.T.; Parent, C.A. $\mathrm{LTB}_{4}$ is a signal-relay molecule during neutrophil chemotaxis. Dev. Cell 2012, 22, 1079-1091. [CrossRef] [PubMed]

24. Monteiro, A.P.; Pinheiro, C.S.; Luna-Gomes, T.; Alves, L.R.; Maya-Monteiro, C.M.; Porto, B.N.; Barja-Fidalgo, C.F.; Benjamim, C.F.; Peters-Golden, M.; Bandeira-Melo, C.; et al. Leukotriene B $_{4}$ mediates neutrophil migration induced by heme. J. Immunol. 2011, 186, 6562-6567. [CrossRef] [PubMed]

25. Doukas, J.; Pober, J.S. IFN-gamma enhances endothelial activation induced by tumor necrosis factor but not IL-1. J. Immunol. 1990, 145, 1727-1733. 
26. Marfaing-Koka, A.; Devergne, O.; Gorgone, G.; Portier, A.; Schall, T.J.; Galanaud, P.; Emilie, D. Regulation of the production of the RANTES chemokine by endothelial cells. Synergistic induction by IFN-gamma plus TNF-alpha and inhibition by IL-4 and IL-13. J. Immunol. 1995, 154, 1870-1878. [PubMed]

27. Libby, P. Inflammatory Mechanisms: The Molecular Basis of Inflammation and Disease. Nutr. Rev. 2007, 65, 140-146. [CrossRef]

28. Fujiwara, N.; Kobayashi, K. Macrophages in inflammation and Allergy. Curr. Drug Targets 2005, 4, $281-286$. [CrossRef]

29. Soehnlein, O.; Weber, C.; Lindbom, L. Neutrophil granule proteins tune monocytic cell function. Trends Immunol. 2009, 30, 538-546. [CrossRef]

30. Patel, S.; Kumar, S.; Jyoti, A.; Srinag, B.S.S.; Keshari, R.S.; Saluja, R.; Verma, A.; Mitra, K.; Barthwal, M.K.; Krishnamurthy, H.; et al. Nitric oxide donors release extracellular traps from human neutrophils by augmenting free radical generation. Nitric Oxide 2010, 22, 226-234. [CrossRef]

31. Moncada, S.; Palmer, R.M.J.; Higgs, E.A. Nitric oxide: Physiology, pathophysiology, and pharmacology. Pharmacol. Rev. 1991, 43, 109-142.

32. Zumerle, S.; Calı, B.; Munari, F.; Angioni, R.; Virgilio, F.D.; Molon, B.; Viola, A. Intercellular Calcium Signaling Induced by ATP Potentiates Macrophage Phagocytosis. Cell Rep. 2019, 27, 1-10. [CrossRef] [PubMed]

33. Desai, B.M.; Leitinger, N. Purinergic and calcium signaling in macrophage function and plasticity. Front. Immunol. 2010, 5, 1-8. [CrossRef] [PubMed]

34. Cunha, F.Q.; Poole, S.; Lorenzetti, B.B.; Ferreira, S.H. The pivotal role of tumour necrosis factor alpha in the development of inflammatory hyperalgesia. Br. J. Pharmacol. 1992, 107, 660-664. [CrossRef] [PubMed]

35. Ferreira, S.H.; Lorenzetti, B.B.; Bristow, A.F.; Poole, S. Interleukin-1 $\beta$ as a potent hyperalgesic agent antagonized by a tripeptide analogue. Nature 1988, 334, 698-700. [CrossRef]

36. Cury, Y.; Picolo, G.; Gutierrez, V.P.; Ferreira, S.H. Pain and analgesia: The dual effect of nitric oxide in the nociceptive system. Nitric Oxide 2011, 25, 243-254. [CrossRef]

37. Mambu, L.; Martin, M.T.; Razafimahefa, D.; Ramanitrahasimbola, D.; Rasoanaivo, P.; Frappier, F. Spectral characterisation and antiplasmodial activity of bisbenzylisoquinolines from Isolona ghesquiereina. Planta Med. 2000, 66, 537-540. [CrossRef]

38. Brasil. Conselho Nacional de Controle de Experimentação animal (CONCEA). Procedimentos-Roedores E Lagomorfos Mantidos Em Instalações de Instituições de Ensino Ou Pesquisa Científica. Resolução Normativa $N^{\circ} 33$, de 18 de Novembro de 2016. Available online: http://www.in.gov.br/materia/-/asset_ publisher/Kujrw0TZC2Mb/content/id/22073702/do1-2016-11-21-resolucao-normativa-n-33-de-18-denovembro-de-2016-22073453 (accessed on 15 October 2019).

39. McIntyre, K. Rodent gavage technique concerns: Avoiding excess mortality. Contemp. Top. Lab. Anim. Sci. 2001, 40, 7.

40. Laranjeira, A.P.; Silva, A.R.; Gomes, R.N.; Penido, C.; Henriques, M.G.M.O.; Castro-Faria-Neto, H.C.; Bozza, P.T. Mechanisms of allergen- and LPS-induced bone marrow eosinophil mobilization and eosinophil accumulation into the pleural cavity: A role for CD11b/CD18 complex. Inflamm. Res. 2001, 50, 309-316. [CrossRef]

(C) 2019 by the authors. Licensee MDPI, Basel, Switzerland. This article is an open access article distributed under the terms and conditions of the Creative Commons Attribution (CC BY) license (http://creativecommons.org/licenses/by/4.0/). 